\title{
EVROPSKI MEJNI REŽIM: TIHOTAPLJENJE LJUDI IN PARADOKS KRIMINALIZACIJE SOLIDARNOSTI
}

\author{
Jelka ZORN
}

COBISS 1.01

\section{IZVLEČEK}

\section{Evropski mejni režim: Tihotapljenje ljudi in paradoks kriminalizacije solidarnosti}

Članek razpravlja o tihotapljenju ljudi v kontekstu evropskega mejnega režima. Oriše teptanje pravice do azila, razčleni demonizacijo tihotapcev in prikaže paradoks kriminalizacije solidarnosti. Kot tržna nelegalna storitev se tihotapljenje ljudi bistveno razlikuje od solidarnosti z ljudmi na poti. Protitihotapska zakonodaja pa ukinja razlike med tihotapljenjem in solidarnostnimi praksami, saj materialna korist ni nujen element kriminalizacije pomoči pri migraciji. Ugotavlja, da »nasilne meje« in državni pregon antagonizem tihotapstvo-solidarnost umeščajo na isti kontinuum in da so solidarnostne prakse upor proti nasilnim mejam, tihotapljenje pa njihov učinek.

KLJUČNE BESEDE: migracije, nasilne meje, azil, solidarnost, tihotapljenje ljudi, aktivizem

\section{ABSTRACT \\ The European Border Regime: People Smuggling and the Paradox of the Criminalization of Solidarity}

The article discusses people smuggling within the European border regime, namely, the right to asylum, the demonization of smugglers, and the paradox of the criminalization of solidarity. As a commercial, illegal service, people smuggling can be seen as the opposite of solidarity with people on the move. Anti-smuggling laws blur their differences since the material benefit of helping people on the move does not qualify as criminal activity. The author presents the embeddedness of the smugglingsolidarity antagonism within the context of violent borders and state persecution. She concludes that solidarity practices are protests against, whereas smuggling is the effect of violent borders.

KEYWORDS: migration, violent borders, asylum, solidarity, people smuggling, activism

Dr. sociologije-socialnega dela v skupnosti, izredna profesorica, Fakulteta za socialno delo Univerze v Ljubljani, Topniška ulica 31, SI-1000 Ljubljana; jelka.zorn@fsd.uni-lj.si, https://orcid.org/00000001-8438-7596 - Članek je nastal v okviru projekta »Evropski režim iregulariziranih migraciji na periferiji EU: Od etnografije do pojmovnika (Hrvatska zaklada za znanost, IP-2019-04-6642) in raziskovalnega projekta »Socialno delo kot nosilec procesov družbenega vključevanja in socialne pravičnosti v Sloveniji (ARRS, P5-0058). — Za dragocene komentarje se zahvaljujem Uršuli Lipovec Čebron, Eli Meh, Maji Ivačič in Asji Hrvatin. Za možnost intervjujev z obsojenimi in s socialnim delavcem se zahvaljujem Upravi RS za izvrševanje kazenskih sankcij. 


\section{UVOD}

Kot smo videli v Avstriji in Sredozemlju, tihotapljenje migrantov ni samo umazan posel, temveč množični umor. (Donald Tusk, predsednik Evropskega sveta, 31. 8. 2015)'

Nadzor migracij na evropskih mejah je del strukturnega nasilja; je odraz razmerij moči v postkolonialnem kontekstu, kjer bogate države omejujejo gibanje ljudi iz revnejših držav (Jones 2017). Kot ilustrira citat takratnega predsednika Evropskega sveta, je odgovornost za ranljivost in umiranje ljudi na poti pripisana tihotapcem. Razbitje tihotapskih združb je evropska politična prioriteta s širokim družbenim konsenzom (Evropska komisija, Migracije in notranje zadeve 2020). V javnem diskurzu so tihotapci neredko izenačeni s trgovci z ljudmi (tj. modernim suženjstvom), ${ }^{2}$ kar izkrivlja razumevanje vzrokov tihotapljenja in odnosov med tihotapci in migranti. Te naracije tihotapljenja ne opredeljujejo kot organiziranje pobega na varnejša ozemlja, ampak kot »zlorabo nesreče« migrantk_ov, v javnost pa pronicajo le negativni primeri (Močnik idr. 2002; Zhang idr. 2018).

$\checkmark$ zgodovinski perspektivi tihotapljenje vidimo $v$ drugačni luči, zlasti kadar besedo »tihotapljenje« zamenja drug termin, npr. "pomoč pri pobegu«. Na tiste, ki so med nacizmom pomagali Judom, Judinjam in drugim preganjanim osebam, danes gledamo kot na heroje oziroma herojinje. ${ }^{3}$ Njihova dejanja so vključevala skrivanje ljudi, ponarejanje dokumentov, skrivno prevažanje in druge načine organiziranega pobega na varnejša ozemlja. Šlo je tako za človekoljubne prakse kot plačane storitve, prve si utirajo pot v javni spomin, druge so utonile v pozabo. llustrativen je časopisni članek, objavljen v Slovencu 2. marca 1941, ki poroča o »navalu Judov na našo mejo« in tihotapljenju judovskih beguncev. Opiše akcijo orožnikov pri razkrinkanju tihotapcev: tihotapce so zadržali v zaporu, judovske begunce pa poslali nazaj čez mejo v Avstrijo, od koder so jih nacisti deportirali na Poljsko (najverjetneje v nacistična taborišča). Diskurz o tihotapljenju je enak kot danes: o posledicah potiskanja beguncev nazaj čez mejo in o tem, da so tihotapci organizirali pobeg za preživetje, se avtor članka ne sprašuje. Bistveno je bilo, da so tihotapce ujeli. Življenja judovskih beguncev so ogrozili orožniki, ne tihotapci.

Državni pregon in z njim usklajeno medijsko poročanje krepita poenostavljeno črno-belo podobo nasilnega in pohlepnega tihotapca (Zhang idr. 2018). To reducirano demonizirano podobo lahko opredelimo kot mit o zlobnem tihotapcu. Dobiček

1 https://www.delo.si/novice/slovenija/cerar-begunce-moramo-sprejeti-brezstrahu.html (15. 12. 2019).

2 Trgovina z ljudmi je suženjstvo, ker gre za neprostovoljna razmerja in prisilno delo. Ključna značilnost je izkoriščanje, ki se nadaljuje tudi po selitvi, ni pa niti nujno, da prehaja državne meje (Bučar Ručman 2014).

GI. Šumi, Luthar (2016) in biografske zgodbe Irene Sendler, Variana Frya, Diane Budisavljević idr. 
je bistveni element demonizacije tihotapstva, ni pa to nujni kriterij za kvalifikacijo kriminalnega dejanja na sodišču. Tretji člen 308. člena se glasi:

Kdor se ukvarja s tem, da tujce, ki nimajo dovoljenja za vstop v Republiko Slovenijo ali prebivanje $v$ njej, nezakonito spravlja na njeno ozemlje, jih po njem prevaža ali jim pomaga pri skrivanju ali kdor dva ali več takih tujcev za plačilo nezakonito spravi čez mejo ali ozemlje države, se kaznuje z zaporom do petih let in denarno kaznijo. (Kazenski zakonik RS, poudarek avtorice)

Besedico »ali« sem podčrtala, ker določa, da element plačila nezakonitega spravljanja na ozemlje ni nujen, da bi bilo neko dejanje kvalificirano kot kriminalno. To pomeni, da zakon zabriše razliko med tihotapljenjem in človekoljubnimi oziroma solidarnostnimi praksami (Allsopp 2017). Protokol ZN proti tihotapljenju migrantov po kopnem, morju in zraku (2000) državam podpisnicam nalaga kriminalizacijo tihotapljenja le kot dejavnost, ki organizatorjem prinaša dobiček oziroma materialne koristi, medtem ko so evropske zakonodajne smernice iz leta 2002 (t. i. facilitator package) ${ }^{4}$ in zakoni v posameznih državah EU dvoumni, kot kaže tudi slovenski primer (Carrera idr. 2018).

Najprej predstavim raziskovalno metodologijo, nato pa poudarim antagonizem mednarodne zaščite in »nasilnih meja«. Koncept je Reece Jones (2017) v istoimenski študiji (Nasilne meje) razvil za poimenovanje prepleta strukturnega, zgodovinsko umeščenega ter neposrednega nasilja, povezanega z mejnimi režimi. Eden od simptomov nasilnih meja je tihotapljenje. Predstavim ga kot kompleksno dejavnost, kot jo vidijo tihotapci, in ne, kot je opredeljena $v$ državnih politikah boja proti tihotapljenju ali kot se pojavlja v medijskem diskurzu. Tihotapci niso homogena skupina. Navajam vmesne vloge, ko so tihotapci obenem begunci, ter način, kako državni pregon običajne prevozne in druge storitve spreminja v tihotapske. Podajam primer, $v$ katerem je tihotapljenje opredeljeno kot politični aktivizem. Na koncu se ukvarjam še s praksami solidarnosti, ki so zaradi državnega preganjanja prav tako skrite in stigmatizirane kot tihotapljenje.

\section{METODOLOGIJA}

Perspektivo svobode gibanja, »pravice do pravic (Arendt 2003), sem razvijala v dveh desetletjih raziskovanja in aktivizma na področju migracij. ${ }^{5}$ Opazovanja z udeležbo

4 Facilitator package sestavljata: Facilitaton Directive (Direktiva Sveta 2002/90/EC od 28. novembra 2002 opredeljuje pomoč pri neavtoriziranem vstopu, tranzitu in bivanju, OJ L 328) in Framework Decision, Svet EU o krepitvi kazenskega pregona za preprečevanje pomoči neavtoriziranega vstopa, tranzita in bivanja, 2002/946/JHA, OJ L 328 (Carrera idr. 2018).

5 Antropološko raziskovanje $v$ azilnem domu in centru za tujce 2000-2002, raziskovanje izkušenj izbrisanih 2002-2012, udeležba z opazovanjem v humanitarnem koridorju 2015 ter v »migrantskih žepih« v Solunu julija 2016, Beogradu januarja 2017, Šidu februarja 2018, Veliki Kladuši novembra 2019 in januarja 2020. 
$v$ beograjskih »barakah«, tj. opuščenem delu železniške postaje (13. 1.-11. 2. 2017) in v obmejnem mestu Šid (8. 2.-15. 2. 2018), kjer so migranti vsakodnevno poročali o policijskem nasilju in push-backih, so me pripeljala k solidarnostnim aktivističnim praksam njihovega preprečevanja. Klasična dilema med aktivizmom in akademskim raziskovanjem je, da je aktivizem obeležen s čustvi in pristranskostjo, medtem ko naj bi bila pozicija raziskovalcev prav nasprotna. Naj bi šlo za dva različna svetova, dvoje različnih pravil. Čeprav produkcija znanja ne more biti objektivna, ker je vselej vpeta $v$ družbeni in zgodovinski kontekst, pa pritisk po nepristranosti raziskovanja trči ob pristranost aktivizma. Raziskovanju ne daje kredibilnost »zunanja« ali »nevtralna« pozicija raziskovalke in raziskovalca, temveč njuna transparentnost pozicioniranosti (Hale 2001). V tem smislu je Donna Haraway (1988) v klasičnem delu feministične epistemologije znanstveno produkcijo povezala $s$ situiranim znanjem. Haraway (1988: 589) trdi, da objektivnost kot »pogled od zgoraj ali pogled od nikoder pod pretvezo nevtralnosti zakriva odnose moči.

Izkušnja, iz katere pišem, je presečišče političnega aktivizma, kriminalizacije solidarnosti in raziskovanja. Sen (2018: 108) zapiše, da je za aktivistično raziskovanje idealna metoda etnografija. Raziskovalne metode v pričujoči raziskavi so kombinacija avtoetnografskega raziskovanja, intervjujev in študija sekundarnih virov. Avtoetnografsko raziskovanje ni pisanje o izkušnji, temveč iz izkušnje (Witkin 2014), umeščene $v$ družbeni kontekst in dopolnjene s teoretsko razpravo nasilnih meja (Khosravi 2010; Jones 2017).

Avtoetnografski pristop $v$ raziskovanju zajema opazovanje, beleženje (vodenje terenskih dnevnikov) in skupinsko refleksijo preprečevanja policijskih push-backov na srbsko-bosanski, srbsko-hrvaški, hrvaško-slovenski, slovensko-avstrijski meji. Dejavnosti preprečevanja push-backov so: prevoz oseb na poti (po ozemlju Hrvaške, Bosne in Hercegovine in v Sloveniji), raziskovanje fizičnega terena, kjer pri pešačenju čez meje ni nadzora, posredovanje informacij, povezanih s potjo, pomoč družini na poti pri nakupu avtomobila za lasten prevoz v Nemčijo, gostitev ljudi na poti v svojem domu ipd. Te dejavnosti, ki smo jih izvajale v manjši skupini, so potekale od konca leta 2016 do septembra 2019. V dnevniških zapisih 10. 2. 2017, 5. 6. 2017, 17. 9. 2017, 23. 3. 2018, 11. 11. 2018, 25. 11. 2018 in 18. 9.2019 sem opisovala dogodke, odnose med udeleženimi in se ukvarjala s tveganjem. Svoj aktivizem opredeljujem s pojmom civilne nepokorščine zaradi namernega kršenja nepravičnih zakonov. Gre za zunajinstitucionalno obliko politične prakse (več o tem glej Celikates 2016). Aktivistke smo bile osredotočene na pomoč konkretnim osebam, vendar je bila ta pomoč obenem tudi protest proti policijskemu nasilju in sistemu nadzora meja (dnevniški zapisi 10. 2. 2017, 5. 6. 2017 in 23. 3. 2018). Kot raziskovalka sem upoštevala etična načela $v$ raziskovanju: spoštovanje samodeterminacije in dostojanstva vseh udeleženih ter transparentnost lastne pozicije kot aktivistke in raziskovalke obenem.

Pomemben raziskovalni uvid mi je omogočila izkušnja kriminalizacije zaradi prevoza dveh afganistanskih prijateljev junija 2017 z obmejnega območja Hrvaške $\checkmark$ notranjost države. Skupaj s sovoznico nas je aretirala policija. Sodnik za prekrške 
naju je spoznal »krive prevoza tujcev [...] pri tranzitu preko območja Republike $\mathrm{Hr}$ vaške $z$ namero da jih [peljeva] v Slovenijo, pri tem pa sta [tujca] na Hrvaško vstopila ilegalno. (Sodnik za prekrške Republike Hrvaške, 28. 5. 2017, dnevniški zapis 5. 6. 2017) Ta izkušnja, ki jo v metodološkem smislu prevajam v avtoetnografsko metodo, je pomembna pri mojem pozicioniranju. Vplivala je na raziskovanje mejnega režima, v katerem so nadzorovani tako migrantke_i in tihotapke_ci kot aktivistke_i.

Naslednja uporabljena raziskovalna metoda je intervju. Tri polstrukturirane pogovore sem opravila z osebami, ki so nudile pomoč ljudem na poti, tudi skrivno pomoč, ki bi lahko bila ali je bila dejansko kriminalizirana. Osebo $\mathrm{H}$. sem intervjuvala 10. 9. 2020, osebo M. 14. 9. 2020 in osebo K. 25. 9. 2020. Poleg polstrukturiranih intervjujev so pomemben uvid omogočili številni neformalni in nestrukturirani pogovori, skupinske refleksije $\mathrm{z}$ istimi in drugimi osebami o taktikah, pomenu, oblikah, poimenovanju in umestitvi solidarnostnih praks (dnevniški zapisi 23. 3. 2018, 11. 11. 2018 in 25. 11. 2018). V Zavodu za prestajanje zaporne kazni Ljubljana sem 9. 10. 2020 intervjuvala moška R. in B., obsojena zaradi tihotapljenja migrantk_ov. V isti ustanovi sem ta dan intervjuvala tudi socialnega delavca.

Sekundarno gradivo, to so intervjuji s tihotapci, ki so jih v celoti objavili drugi raziskovalci (Khosravi 2010; Malek 2020; Močnik idr. 2002), je vsebinsko usklajeno z mojimi intervjuji. Pomemben vir podatkov o tem, kako tihotapci gledajo nase, so etnografske študije raziskovalcev na dolgotrajnejših antropoloških terenih v Turčiji, Afganistanu, Nigru, Etiopiji, Somaliji in Mehiki (Mohamamadi idr. 2019; Achilli 2018; Ayalew Mengiste 2018; Majidi 2018; Achilli 2017).

Pomembno sekundarno gradivo je tudi diplomska naloga Ane Lilije (2020) o kriminalizaciji solidarnosti ter zapisnik policije in tožilstva, ki ga je vanjo vključila kot del raziskovanega gradiva. Vanj umeščam tudi več javnih pričevanj kriminaliziranih oseb zaradi reševanja migrantk_ov iz morja in zagovorniških praks na področju pravice do azila (Klemp 2019; Rackette 2019; Mardini 2020; Are You Syrious 2018).

\section{PRAVICA DO MEDNARODNE ZAŠČITE IN NASILJE NA MEJAH}

Zakon o mednarodni zaščiti RS temelji na mednarodni Konvenciji o statusu beguncev iz leta 1951. Konvencija, po drugi svetovni vojni sprejeta kot odgovor na opustošenje, množične migracije in milijone ljudi brez državljanskega statusa, je bila pomembna civilizacijska pridobitev. Danes evropski mejni režim pravico do mednarodne zaščite uničuje. S stališča države gre za temeljni antagonizem, ki je v tem, da bi dosledno spoštovanje pravice do mednarodne zaščite pokazalo odvečnost militariziranega nadzora meja ter absurdnost boja proti tihotapskim mrežam, katerega učinek je krepitev tihotapstva.

Medtem ko vlade za ranljivost migrantov krivijo tihotapce, kot ilustrira uvodni citat, ljudje na poti poročajo o nasilju in nezakonitem ravnanju policije. Namesto možnosti za mednarodno zaščito ljudje na mejah večinoma izkusijo mednarodno 
zavračanje, in to kot verižno potiskanje (push-back) nazaj po balkanski poti. Čeprav so potiskanja nedovoljena tako po mednarodnem pravu kot domači zakonodaji in so javno razkrita ter dokazana, policija z njimi nadaljuje. $V$ poročilih Varuha človekovih pravic RS (2018), Amnesty International Slovenije (2018), Info Kolpe (2019), Are You Syrious (2020a), Border Violence Monitoringa Network (2020) so zbrana pričevanja migrantov. Kažejo sistematično kršitev človekovih pravic do dostojanstva, informiranosti in pravnih sredstev ter načine mučenja. Ne gre za posamezne slabe prakse ali izredne dogodke. Fizično nasilje policije $z$ vidnimi sledmi na telesih ljudi je pogosto zlasti na Hrvaškem, kar naj bi bila strategija odganjanja potencialnih migrantk_ov. Vidne sledi mučenja so telesne oznake institucionalizirane neenakosti, analogne drugim zgodovinskim obdobjem. ${ }^{6}$ Fizično nasilje spremljajo poniževanje, uporaba strelnega orožja in psov, uničevanje telefonov, odvzem denarja, prisilno slačenje ter odvzem obutve in oblačil. Slovenska policija očitke o potiskanjih na Hrvaško zavrača. Kot ocenjuje Are You Syrious (2020b), je bilo v zadnjih dveh letih iz Slovenije na Hrvaško potisnjenih 16.000 ljudi. Sodišče v Genovi je maja 2020 vračanje prosilcev za azil iz Italije $v$ Slovenijo prepovedalo $z$ argumentom nehumane obravnave in ilegalnih policijskih potiskanj na Hrvaško, od tam pa v Bosno in Hercegovino ali Srbijo (prav tam).

Od leta 2016 o push-backih na Balkanu redno poroča nevladna iniciativa Border Violence Monitoring Network. Do oktobra 2020 so objavili 844 pričevanj migrantov o policijskem potiskanju in nasilju na balkanski poti. Zavračanje migrantov policija imenuje nadzor meje. Azilni sistem je neločljivo spojen z (nasilnim) nadzorom meja, zaradi česar sva Lipovec Čebron in Zorn (2016) zapisali, da je azil farsa. Navajam primer, ki ponazarja policijski diskurz o nadzoru meje in pravici do azila. Ministrica za notranje zadeve RS je na tiskovni konferenci pojasnila:

Je pa res, da niso samo nevladniki in novinarji tisti, ki svetujejo tujcem, naj izrazijo namero zaprosit za mednarodno zaščito, ampak so to predvsem tihotapci, ki postopek oziroma zlorabo postopka vključujejo v svoj poslovni model tihotapljenja čez državno mejo. [...] zloraba azilnega postopka [je] najbolj [...] uporabljen način prestopanja državne meje v RS. (Ministrstvo za notranje zadeve RS 2018)

V tej shizofreni situaciji naj bi bilo mogoče oboje hkrati: uresničevanje pravice do mednarodne zaščite in zavarovanje meje pred prihodom migrantov oz. beguncev. $Z$ bojem proti tihotapljenju države blažijo antagonizem nadzora in pravice do azila (Watson 2015). Po mednarodnih standardih so prihodi prosilcev za azil dovoljeni oz. dekriminalizirani (Protokol ZN proti tihotapljenju migrantov po kopnem, morju in zraku 2000; Konvencija o statusu beguncev 1951). Boj proti tihotapljenju omogoča stalen militariziran nadzor meje, pri čemer prikaže tihotapstvo kot zločin, ki ne le poškoduje

$6 \quad \mathrm{~V}$ drugih zgodovinskih obdobjih je bila institucionalizirana neenakost $\mathrm{v}$ telesa vtisnjena $z$ bičanjem sužnjev $v$ času sužnjelastništva in s tetoviranjem številk zaprtim v nacističnih taboriščih. 
ljudi na poti, ampak tudi spodbuja nelegalne migracije, kot je razvidno iz navedenega citata.

O tihotapcih kot krivcih za migracije in kriminaliziranju informiranja migrantov o pravici do azila poroča tudi Amir Heidari (v Khosravi 2010: 105). Heidari sebe predstavi kot aktivista, ki je samo na Švedskem zaradi tihotapljenja večinoma Kurdov (na Švedsko je s ponarejenimi dokumenti pomagal približno 40.000 ljudem) v zaporu presedel 14 let. Antropolog, tudi sam begunec, Shahram Khosravi (2010) ga je intervjuval v zaporu. Heidari svojega »dela s prebežniki« ${ }^{7}$ ne skriva. Delo nadaljuje tudi v zaporu, kjer je izdal knjižico navodil, kako podati vlogo za azil, kako se predstaviti policistom oz. azilnim inšpektorjem ter kako se obnašati na letališčih. Njegovo delo je kriminalizirano (kot ponazarja navedeni odlomek policijskega govora), delo odvetnikov pa cenjeno, razmišlja Heidari, čeprav oboji informirajo o azilnem postopku (v Khosravi 2020).

\section{STALIŠČA TIHOTAPCEV IN TIHOTAPK: POMOČ PRI BEGU IZ VOJNE IN IZHODU IZ REVŠČINE}

\section{Motivacija za delo in vpetost tihotapcev v skupnosti}

$\checkmark$ vladnem in medijskem diskurzu se $s$ tihotapljenjem povezane teme vrtijo okoli organiziranega kriminala, trgovine z ljudmi in terorizma, najpogostejše ob tem uporabljene besede pa so: zloraba, mafija, dobiček, pranje denarja, izkoriščanje nesreče beguncev (Evropska komisija, Migracije in notranje zadeve 2020). Etnografinje_i opozarjajo, da gre pri tem za poenostavljene predstave o migrantkah_ih kot pasivnih žrtvah na eni strani in tihotapcih kot prežečih nevarnih kriminalcih na drugi. Vloge so neredko prepletene, $v$ tihotapljenje so vključeni moški in ženske, včasih celo otroci. (Mohamamadi idr. 2019; Ayalew Mengiste 2018; Majidi 2018; Zhang, Shanchez, Achilli 2018)

Pozicije begunec-tihotapec niso vselej ločene. Luigi Achilli (2017: 138) predstavi Mahdija, fanta iz Sirije. Zaradi oboroženih spopadov je bilo območje njegovega doma opustošeno, primanjkovalo je hrane, ljudje so bili bolni, stopnja umrljivosti je bila visoka. Mahdi se je povezal s sovaščanom Abujem Jihadijem, ki je privolil, da spravi njegovo družino v Evropo, s pogojem, da Mahdi sodeluje pri tihotapljenju in $s$ tem poplača strošek poti. Ko ga je raziskovalec Achilli vprašal, ali je bila njegova vključitev v tihotapski posel prostovoljna ali prisilna, je odgovoril: »Glej, to je nevarno delo, če te ujameta turška ali grška policija, lahko dobiš 10 do 15 let zapora. Torej, če bi lahko izbiral, tega ne bi nikoli počel. Toda - hamdulillah [hvala Alahu] - Abu Jihad

7 Besedno zvezo »delo s prebežniki« je sogovornik R. uporabil za svoje aktivnosti in aktivnosti svojega znanca, ko sem z njima govorila v zaporu. Oba prestajata zaporno kazen na podlagi 308. člena Kazenskega zakonika (pomoč pri nedovoljenem prehodu meje). 
je bil tam, ko sem ga potreboval: če ga ne bi bilo, bi jaz in moja družina v Siriji umrli.« (Achilli 2017: 138)

O izkušnji tihotapljenja zaradi lastne migracije je poročal tudi fant $\mathrm{S}$. iz Afganistana, s katerim je poglobljen intervju opravila Nastja Malek (2020). S., ki je pri desetih letih ostal sam, je najprej migriral v Iran, zatem v Turčijo, kjer se je s 13 leti vključil $\checkmark$ tihotapljenje: „V tihotapljenje sem se vpletel, ko sem sam potreboval pomoč. Na tej poti vsi potrebujejo tihotapca. [...] Vsak raje plača za svojo varnost, kot da hodi po neznanem terenu. $V$ begunskem kampu sem srečal človeka, ki je delal na tem področju in me je vključil. Bil sem zadržan otrok. Moral sem se zanesti nase.« (Malek 2020: 83) Na poti je preživel več težkih, travmatičnih let. Sedaj ima mednarodno zaščito v Nemčiji, kjer je uspešen študent in si želi le normalno živeti (Malek 2020).

Več avtorjev je poudarilo zaupne odnose med migranti in tihotapci; nekateri na poti skupaj živijo, kuhajo in jedo isto hrano. Tekalign Ayalew Mengiste (2018) take odnose, kolektivne prakse in specifično znanje za mobilnost, vključno z znanjem iz diaspore, imenuje skupnosti znanja. Družinske in prijateljske vezi pa tudi v teh situacijah niso garancija za neizrabljajoče in nenasilne odnose. $V$ zaostrenih razmerah ilegaliziranih poti se zlorabe in izkoriščanje povečajo tudi znotraj etničnih in sorodstvenih povezav (Lilija 2020; Achilli 2018; Malek 2020), čeprav so tihotapci podvrženi istim neformalnim pritiskom skupnosti, da storitve, tako kot vsi drugi podjetniki, opravljajo etično (Mohammadi idr. 2019). »Tema je zelo čustvena. Tudi sam sem bil leta 2001 pribežnik. Sodišča pa gledajo na to črno-belo. [...] Dolžen sem pomagati sonarodnjaku, tudi če ga ne poznam osebno, « se je R. spominjal obdobja, ko so ga sovaščani s Kosova, ki so potovali v Italijo, prosili za pomoč. »Ko nas ustavi policija, navaden revež ne more nič. Če greš na sodišče in imaš denar za odvetnika, je vse drugače. [...] Tu smo vsi revni, « je pojasnil svoje okoliščine, občasno tihotapsko dejavnost in njene posledice. (intervju z R. na prestajanju zaporne kazni, 9. 10. 2020)

Tudi nekateri sirski begunci, ki pomagajo pri odpravljanju ljudi na varnejša ozemlja, to dejavnost pojasnjujejo kot etično dolžnost pomagati sodržavljanom, vendar zase termina tihotapec, zaradi stigmatizacije in stereotipiziranih predstav, ne uporabljajo (Achilli 2018). Podobno so afganistanski tihotapci, ki ljudem z nevarnih območij pomagajo priti na varno, svoje delo opredelili kot humanitarno: »Mi smo tisti, ki pridemo, ko nihče ne more pomagati, « je ena od izjav, ki je obenem tudi naslov študije (Mohammadi idr. 2019: 6). »Če ljudje ne bi mogli migrirati v Pakistan ali Iran, verjemite, da bi pol države umrlo od lakote, « je povedal eden od informatorjev v Afganistanu (Mohammadi idr. 2019: 11). Podobno pove tihotapec iz Slovenije: »Nikoli mi ni bilo žal, da sem to počel, saj sem se miril, da sem reševal ljudi« (Močnik idr. 2002: 223).

Majidi (2018) poudari, da je pomoč pri imigraciji tem bolj vpeta $v$ skupnosti, iz katerih prihajajo migrantke_i, kolikor so bliže domu, zaradi česar so meje med solidarnostjo in plačano dejavnostjo včasih zabrisane. Taka situacija je bila v Sloveniji v devetdesetih letih značilna vse do odprave viz, ko so slovenski državljani tihotapili svoje sorodnike in prijatelje iz držav na območju nekdanje Jugoslavije (intervju s socialnim delavcem, 9. 10. 2020; Močnik idr. 2002). 


\section{Organiziranost tihotapljenja}

Vladni in medijski diskurzi tihotapljenje značilno prikazujejo kot hierarhično organizirano, in to s pomočjo velikih transnacionalnih mrež iz več držav in kontinentov, ki poslujejo skupaj z drugimi kriminalnimi družbami pri tihotapljenju drog, trgovini z ljudmi in v povezavi s terorizmom. Kot poudari Gabriella Sanchez (2017) v sintezi etnografskih študij, večina oseb, ki tihotapi, dela neodvisno, s pomočjo osebnih poznanstev. Tako lahko razumemo tudi izjavo fanta S.: »Ljudje ne delajo sami. Preveč je tvegano. Za to delo potrebuješ celo mrežo ljudi, ki jim lahko zaupaš in ki ti bodo pomagali.« (S. v Malek 2020: 84) Večinoma posamezne, specifične naloge (vodenje skozi puščavo, gozd, kuhanje, vožnje, nudenje prenočišča, oglaševanje storitev ipd.) opravljajo koordinirano z drugimi pomagači pri nelegalnih prehodih (Sanchez 2017). »V naši skupini smo bili zadolženi za različne naloge. Jaz sem bil za stike z migranti. Veliko časa sem preživel na bazarju, čakal ljudi in jih informiral, " je izkušnja takrat mladoletnega S. (v Malek 2020: 84). Tudi solidarnostna pomoč je skupinska, utemeljena na medsebojnem zaupanju vseh udeleženih (sinteza intervjuja z M. in H.; dnevniški zapis 23. 3. 2018).

Tihotapci na daljših ilegaliziranih poteh se med seboj ne poznajo, saj so iz različnih mest in držav (Sanchez 2017: 14). Moški in ženske pogosto opravljajo spolno specifične naloge, sodelovanje $z$ lokalnimi prebivalci je običajno: »Veliko kmetov nam je dalo hrano, starejše ženske pa namestitev. Če imaš denar, vsi sodelujejo $s$ tabo. Ob tem pa nihče nič ne vidi; vsi so pomagali in se pretvarjali, da ne vedo nič.» (S. v Malek 2020: 83)

Taksisti na balkanski poti so tipičen primer sodelovanja lokalnih prebivalcev in njihovih servisov: "Lahko delujejo v lastni (ne)organizaciji, torej kot posamezniki, ki samoiniciativno prebežnikom ponudijo prevoz, ali pa so vključeni v združbe« (Močnik idr. 2002: 209). Eden od ljubljanskih taksistov, s katerim sem se večkrat pogovarjala (v letih 2018 in 2019), je povedal, da je vozil tudi migrante (kot vse druge stranke), vendar ne čez mejo, jim je pa svetoval, kje se lahko na nadaljnji poti proti Italiji izognejo policijskemu nadzoru.

$\mathrm{Na}$ tej točki so običajne komercialne storitve lahko razumljene in preganjane kot tihotapske. Na balkanski begunski poti so beograjski taksisti v obdobju pred vzpostavitvijo državnega koridorja (2015/16) migrantske družine in posameznice_ke množično vozili v Subotico. Mnogi so bili kriminalizirani, ne glede na to, ali so vozili po običajni tarifi ali pa so situacijo migrantk_ov izkoriščali za zvišanje cen prevoza (Stojić Mitrović, Meh 2015). »Ali moramo mi razmišljati o tem, ali imajo naše stranke dokumente?« se je spraševal eden od taksistov, ki so mu za čas trajanja postopka na sodišču odvzeli vozilo. Takrat so v Srbiji odvzeli približno 200 taksijev. (Glas Subotice 2015) Podobno kriminalizacijo so doživljali lastniki mladinskih hostlov v Beogradu in drugje, če je policija odkrila, da so gostili ljudi brez dokumentov oz. brez začasnega dovoljenja za zadrževanje (Stojić Mitrović, Meh 2015). Enako je bilo v Bihaću, kjer je policija denarno kaznovala osebe, ki so ljudem na poti oddajali sobe ali hiše po tem, 
ko se je leta 2018 balkanska begunska pot preusmerila čez Bosno in Hercegovino (Veršić 2019). Kot uradni kandidatki za vstop v EU morata Srbija ter Bosna in Hercegovina harmonizirati svojo zakonodajo o nadzoru meja, kar je povezano s preganjanjem »tihotapcev«: taksistov, hotelirjev in drugih, ki oddajajo sobe migrantkam_om, pa tudi tistih, ki jih sprejmejo v svoj dom (Stojić Mitrović, Meh 2015; dnevniški zapis 18. 2. 2018, Šid). Podoben proces kriminalizacije, ki običajne storitve ali podjetnike spreminja $v$ tihotapce, poteka $v$ oddaljenem nadzoru evropskih meja $v$ nekaterih afriških državah; v nadaljevanju navajam primer.

\section{Primer spremenjene zakonodaje: Iz prevoznikov v tihotapce}

Za razumevanje konteksta ustvarjanja tihotapstva je pomembna študija Sarah Lunaček (2019), ki je s pomočjo dolgoletnega obiskovanja Agadeza (Niger) pokazala škodljivost eksternalizacije evropskih meja v Afriki. Evropski nadzor se je po padcu Gadafija iz Libije pomaknil v Niger, kar je povzročilo kriminalizacijo do tedaj običajnih potovanj čez Saharo (Lunaček 2019; Brachet 2018). Leta 2015 je nigrska vlada pod pritiskom EU sprejela zakon, ki kriminalizira sodelovanje pri mednarodnih migracijah. Zakon je namenjen preprečevanju trgovine $z$ ljudmi in zaščiti žrtev, pri čemer ne kriminalizira le trgovine $z$ ljudmi, ampak tudi transport migrantov, ki je naenkrat dobil status tihotapljenja. Posledica tega zakona je, da so nemudoma prepovedali in kriminalizirali

ves obstoječi transport čez Saharo ter vse z njim povezane dejavnosti. Žandarmerija je v skladu z zakonom zaplenila vozila dotlej legalnih prevozniških agencij (več kot 100 vozil pick up), njihove lastnike, ki so se čez noč prekvalificirali v tihotapce, pa zaprla - nekateri so zaprti še danes. Prepovedali so transport ljudi s tovornjaki, prav tako je prepovedano migrantom oddajati sobe in jim streči v restavracijah. (Lunaček 2019: 65)

Zaradi kriminalizacije prej običajnih transportov in drugih potovanj so se cene močno zvišale. Če povzamem, ukrepi, ki jih vsiljuje EU, pogosto ustvarijo tihotapljenje, deloma pa tudi trgovino z ljudmi (Lunaček 2019: 65). Primeri spremenjenih politik pokažejo, kako države ustvarjajo pogoje za tihotapljenje, čeprav je deklarativno njihov namen ravno obraten.

\section{POLITIČNI AKTIVIZEM IN SOLIDARNOST}

V kontinuum tihotapljenje-solidarnost lahko umestimo že večkrat omenjenega Amirja Heidarija, ki je s pribežniki delal za denar, a iz političnih razlogov. Leta 1980 je bil kot aktivist socialističnega gibanja ranjen. Zdravil se je na Švedskem, kamor je odšel preko Turčije. Ker so Kurde takrat povsod zavračali, se je vrnil v Turčijo, da bi 
pomagal svojim ljudem: »Na tisoče Kurdom je grozila deportacija v Iran. Nihče ni pomagal, zato sem začel svoje gibanje. V Istanbulu sem prodajal tepihe in s profitom od prodaje pošiljal Kurde v Evropo.« Šele pozneje je pomagal na Švedsko in v druge zahodne države za plačilo tudi drugim (v Khorsavi 2010: 109). Z njihovimi plačili je financiral pot aktivistk_ov brez denarja. $V$ zvezi s profitom, ki je največji element demonizacije tihotapcev, je povedal, da se je $z$ denarjem od dela $z$ begunci tudi preživljal, saj drugega dela ni imel. »Temu rečejo profit. Če je to res, kaj pa Rdeči križ? Plačujejo svoje zaposlene, je to tudi profit? (v Khorsavi 2010: 107) O svojem delu govori odprto: »Nikoli nisem skrival, kaj delam« (v Khorsavi 2010: 108). »Sem svoja lastna potovalna agencija. Delam s tistimi, ki jim zavrnejo vize in potne liste« (v Khorsavi 2010: 108).

Njegova antirasistična in antikapitalistična stališča so podobna stališčem solidarnostnih skupin, ki pomagajo preživeti ljudem na poti v grških mestih in na otokih, $v$ Beogradu, Subotici, Šidu, Veliki Kladuši, Calaisu itd. in ki rešujejo ljudi iz Sredozemskega morja (Tazzioli 2018). Pot migrantov je prežeta s policijskim nasiljem in push-backi. Sogovornica, ki deluje v različnih solidarnostnih skupinah na balkanski poti, je povedala: »Biti priča takšni stopnji razčlovečenja, nasilja in brutalnosti je v meni vzbudilo to, da moram nekaj narediti. In to, kar ljudje zares potrebujejo, je $v$ končni fazi, da pridejo čez.» (intervju z M., 14. 9. 2020) Pomoč pri tem, da pridejo »čez«, je po njenem mnenju raznolika, od informiranja o izogibanju policijskemu nadzoru, do tega, da lokalno prebivalstvo ne pokliče policije, ko v gozdu vidi ljudi na begu. Lahko pomeni nakup SIM kartice ali vozovnice za avtobus, saj so včasih za nebelo osebo že to tvegana dejanja, ki se končajo s policijskim push-backom iz države nazaj po balkanski poti.

Druga sogovornica je povedala: »Prijatelja sva peljali v Italijo, ker ga voznik ni vzel na avtobus, čeprav smo kupili vozovnico. Kaj naj bi v tistem trenutku? Nisva ga mogli pustiti kar tam, na avtobusni postaji. Po vsem tem, kar je že dal skozi« (intervju s K., 25. 9. 2020). Trenutna spontana odločitev je izhajala iz poznavanja nepravičnih razmer.

Tretja oseba, ki pomaga ljudem na poti, pa solidarnostno dejavnost utemeljuje s svojim poklicem. Pomagati ljudem pri mobilnosti se ji kot socialni delavki zdi »skoraj dolžnost. To je zame praktično del opisa poklica. Niti ni vprašanje legalnosti. Če to počnem kot socialna delavka, potem je moje dejanje legitimno, ker je dejansko znotraj tega, kar sem se naučila, da je definicija socialnega dela. Ker če tega ne počnem, si ne morem reči socialna delavka.« (intervju s H., 10. 9. 2020)

Podobno sem 5. 6. $2017 \mathrm{v}$ dnevnik zapisala tudi sama, ko sem policistom pojasnjevala svoje delovanje:

Skupina kriminalistov, kakšnih 8, iz treh avtov, se je zgrnila okoli nas kot da smo najhujši kriminalci. [...] Čakali so cel dan in potem zagledali naju. [...] Glavnemu kriminalistu sem rekla: "Sem socialna delavka in zgolj opravljam svoje delo. Vi ali vaši kolegi ste nasilni in vračate ljudi nazaj v Srbijo. Nihče ne more zaprositi za azil. Če ne bi bile take razmere, nama fantov ne bi bilo treba voziti.» 
Dadusc in Mudu (2020) ugotavljata, da smo v danih razmerah kriminalizacije solidarnosti in preprečevanja spontanih, avtonomnih odzivov vsi interpelirani $v$ čuvaje meje. In obratno, če nisi čuvaj(ka) meje, si lahko v določenih okoliščinah osumljen(a) tihotapstva. Enako je sogovornica M. opazila v različnih državah na balkanski begunski poti, tudi v Sloveniji: „Ljudje, ki živijo ob meji in jim je grozno to [težko pot migrantov] gledat, pomagajo in naenkrat jih policija preganja, piše kazni, zapira lokale, ki strežejo migrantom, prepoveduje Western Union.« (intervju z M., 14. 9. 2020)

\section{Primer zagovorništva na slovenski meji}

V naslednjem dramatičnem primeru sta policija in tožilstvo tri aktivistke osumila storitve kaznivega dejanja sodelovanja pri prepovedanem prehodu meje. Namen aktivistk je bil preprečiti push-back sirskih državljanov, da bi lahko potem, ko so že bili na slovenskem ozemlju, na najbližji policijski postaji podali vlogo za azil. V nadaljevanju opisujem zaplet, povzet po avtoetnografskem delu diplomske naloge Ane Lilije (2020) in več neformalnih pogovorih z njo.

V mrzli decembrski noči sta se dve osebi odpeljali na lokacijo ob hrvaški meji in tam iskali tri fante, ki so pobegnili iz Sirije. Fantje so jima poslali svojo lokacijo, zato sta jih zlahka našli, še pred tem pa sta naleteli na policiste in jim pojasnili svojo skrb glede njihove vloge za azil. Fantom sta dali hrano in vodo. Policisti na lokacijo ob meji niso poklicali le avta, ki je fante odpeljal na policijsko postajo, kjer so podali vlogo za azil, temveč tudi kriminaliste, ki so aretirali aktivistki. Aretirali so tudi osebo, ki je čakala pred policijsko postajo. Na policijski postaji so se kriminalisti, ki so vodili postopek, vedli kot rešitelji aktivistk pred morebitnim spolnim nasiljem treh sirskih državljanov. Dejansko so kriminalisti (in ne begunci) temeljno ogrozili občutek osebne varnosti in zaupanja v institucije treh pridržanih oseb. Policija je zapisnik dogodka in izjave pridržanih poslala na tožilstvo, ki je aktivistke osumilo storitve kaznivega dejanja po tretjem odstavku 308. člena Kazenskega zakonika RS. Tožilec je zapisal, da varnost ni samoumevna in da njihova dejanja ogrožajo varnost Slovenije in EU. V leto dni trajajočem predkazenskem postopku se je preiskovalna sodnica odločila, da elementov kaznivega dejanja ni in da sodišče ne bo uvedlo kazenskega postopka. Čeprav kazenski postopek ni bil uveden, pa je šlo za zastraševanje, ogromen psihični pritisk in stroške odvetnikov zagovornic človekovih pravic.

Carrera idr. (2018), Jalušič (2019), Zaviršek (2017) in druge raziskovalke_ci poudarjajo, da tak odnos državnih organov do ljudi, ki delujejo avtonomno in solidarno, uničuje odgovornost civilne družbe, svobodo združevanja in svobodo govora. Podatek iz aprila 2019 kaže, da v državah EU proti posameznicam_kom poteka 158 kazenskih postopkov ter 16 proti NVO-jem (Vosyliūtè, Conte 2019: 6). Zgoraj opisani primer v to statistiko ne bi bil vštet, saj kazenski postopek ni bil uveden. Jalušič (2019) je opozorila, da so to razmere, $v$ katerih so oboji, tako migrantke_ti kot domačinke_i, dehumanizirani in vzpostavljeni kot odvečni. Travmatična izkušnja preganjanja, tako 
kot nasilje na mejah, ne pomenita, da se ljudje uklonijo in sprejmejo grožnje države. Pia Klemp (2019), ena od kriminaliziranih kapitank, katerih posadke so reševale ljudi pred utopitvijo $v$ Sredozemskem morju, je izjavila, da bi spet naredila isto, tj. reševala ljudi iz morja, in to »ne navkljub kriminalizaciji, ampak toliko bolj prav zaradi tega«. Podobno ugotavljajo Lipovec Čebron idr. (2019) v raziskavi o kriminalizaciji gostoljubja $v$ Veliki Kladuši. Nekateri se represivnim državnim ukrepom podredijo in prekinejo stike z migranti, drugi s prepovedmi barantajo, tretji pa se kriminalizaciji odkrito uprejo in nadaljuje gostoljubne prakse.

\section{ZAKLJUČEK}

Strinjam se z Reece Jones (2017), da so meje vir nasilja, ne pa odgovor nanj. Države strukturno in neposredno nasilje nad migrantkami in migranti normalizirajo tudi s pomočjo demoniziranja in preganjanja tihotapcev. $V$ teh razmerah policija onemogoča svobodo gibanja in pravico do mednarodne zaščite. Za ljudi na poti so nevarni tako nasilni policisti kot izkoriščevalski tihotapci. Kljub pogostim slabim tihotapskim praksam - to so popolnoma neregulirane tržne storitve - sem preverila mit o zlobnem tihotapcu. Povzela sem antropološke raziskave, ki temeljijo na intervjujih s tihotapci. Svojo dejavnost razumejo kot servis za mobilnost, torej kot del rešitve in ne kot del problema. Prikazala sem tudi »vmesne« prakse, ki bi jih glede na laično razumevanje tega kaznivega dejanja težko umestili pod pojem tihotapljenja ljudi. Tihotapljenje prikazujem kot učinek nasilnih meja in ne kot »notranje« značilnosti ljudi iz drugih držav ali kultur.

Definicija tega kaznivega dejanja v EU velja tudi za prakse solidarnosti z migranti in reševanje ljudi na morju (Klemp 2019; Rackette 2019; Mardini 2020; Tazzioli 2018; Vosyliūtè, Conte 2019; Carrera idr. 2018; Allsopp 2017). Izkoriščanje oziroma materialna korist ni nujen element za kvalifikacijo tihotapljenja ljudi kot kaznivega dejanja, zato se tihotapci, lokalno prebivalstvo s svojimi običajnimi servisi ter solidarnostne prakse sorodnikov, prijateljev in aktivistov lahko znajdejo na istem kontinuumu kriminalizacije. Zaradi kakršnekoli pomoči ali sodelovanja z ljudmi na poti (z osebami, ki nimajo ustreznih dokumentov) smo vsi interpelirani v čuvaje meje. Za ta uvid je bila ključna avtoetnografska raziskovalna metoda. Čeprav s tveganjem stigmatizacije, je lastna izkušnja solidarnostnih praks kot tudi kriminalizacije močan motiv za raziskovanje in pisanje.

Pred stigmatizacijo se je mogoče braniti vsaj na dva načina: $z$ istim policijskim diskurzom, s katerim smo napadeni (»nismo tihotapci«, pri čemer mit o zlobnem tihotapcu ostaja nedotaknjen), ali z razčlenitvijo demonizacije tihotapljenja. V članku sem se odločila za slednje, ker želim pokazati na problematičnost mejnega režima kot takega. Migranti iščejo tihotapske storitve za mobilnost, ilegalizacija pa povečuje njihovo ranljivost. Mejni ukrepi spodbujajo prav tihotapljenje in trgovino z ljudmi, proti katerim se borijo, in zato zgrešijo svoj namen (Achilli 2017: 139). 
Kljub temu da organi državnega pregona tihotapljenje in solidarnostne prakse enačijo, v članku pokažem, da se dejavnosti tako etično kot politično pomembno razlikujeta. Prva je »normalni« del svobodnega trga (tj. izkoriščanja in plačljivosti v kapitalističnem sistemu), druga pa je pomoč ljudem na poti ter obenem protest proti mejnemu režimu onstran tržnih odnosov. Zato solidarnostne prakse razumem kot upor proti nasilnim mejam, tihotapljenje pa kot njihov učinek.

\section{LITERATURA IN VIRI}

Achilli, Luigi (2018). The "Good" Smuggler: The Ethics and Morals of Human Smugglings Among Syrian. The ANNALS. American Academy of Political and Social Science 676/1, 77-95, https://doi.org/10.1177/0002716217746641.

Achilli, Luigi (2017). "Smuggling and Trafficking in Human Beings at the Time of the Syrian Conflict." Human Trafficking and Exploitation: Lessons from Europe (ur. Belachew Gebrewold, Johanna Kostenzer, Andreas Th. Müller). London: Routledge, 129-146, https://doi.org/10.4324/9781315212449-8.

Allsopp, Jennifer (2017). Solidarity, Smuggling and the European Refugee Crisis: Civil Society and its Discontents. Diritto, immigrazione e cittadinanza 3/2017, https:// www.academia.edu/35030187/Solidarity_Smuggling_and_the_European_ Refugee_Crisis_Civil_Society_and_its_Discontents (2.5.2020).

Amnesty International (2018). Slovenia: Push-backs and Denial of Access to Asylum. Findings of the Research Mission in Velika Kladuša and Bihać, June 2018, https:// www.amnesty.si/media/uploads/files/Slovenia\%20-\%20Push-backs\%20 and\%20denial\%20of\%20access\%20to\%20asylum\%2C\%20Amnesty\%20International(1).pdf (27. 11. 2019).

Arendt, Hannah (2003). Izvori totalitarizma. Ljubljana: Študentska založba.

Are You Syrious (2018). When Governments Turn Against Volunteers. The Case of AYS, https://medium.com/are-you-syrious/ays-special-when-governments-turnagainst-volunteers-the-case-of-ays-81fcfe0e80e7 (4. 3. 2020).

Are You Syrious (2020a), https://areyousyrious.medium.com (10. 11. 2020).

Are You Syrious (2020b). Italian Court Stops Deportation to Slovenia, Meanwhile Pushbacks Continue, 3. 6. 2020, https://medium.com/are-you-syrious/ays-specialitalian-court-stops-deportation-to-slovenia-meanwhile-pushbacks-continue-a0370c30cd02 (25. 6. 2020).

Ayalew Mengiste, Tekalign (2018). Refugee Protections from Below: Smuggling in the Eritrea-Ethiopia Context. The ANNALS. American Academy of Political and Social Science 676/1, 57-76, https://doi.org/10.1177/0002716217743944.

Border Violence Monitoring Network (2020), https://www.borderviolence.eu (2. 10. 2020). 
Brachet, Julien (2018). Manufacturing Smugglers: From Irregular to Clandestine Mobility in the Sahara. The ANNALS. American Academy of Political and Social Science 676/1, 16-35, https://doi.org/10.1177/0002716217744529.

Bučar Ručman, Aleš (2014). Migracije in kriminaliteta: Pogled čez meje stereotipov in predsodkov. Ljubljana: Založba ZRC, ZRC SAZU.

Carrera, Sergio, Vosyliūtè, Lina, Smialowski, Stephanie, Allsopp, Jennifer, Sanchez, Gabiella (2018). Fit for Purpose? The Facilitation Directive and Criminalisation of Humanitarian Assistance to Irregular Migrants: 2018 update, https://www.europarl. europa.eu/RegData/etudes/STUD/2018/608838/IPOL_STU(2018)608838_EN.pdf (9. 4. 2020).

Celikates, Robin (2016). Rethinking Civil Disobedience as a Practice of Contestation - Beyond the Liberal Paradigm. Constellations 23/1, 37-45, https://doi. org/10.1111/1467-8675.12216.

Dadusc, Deanna, Mudu, Pierpaolo (2020). Care Without Control: The Humanitarian Industrial Complex and the Criminalisation of Solidarity. Geopolitics 1-26, https:// www.tandfonline.com/doi/abs/10.1080/14650045.2020.1749839?journalCode=fgeo20 (20. 9. 2020), https://doi.org/10.1080/14650045.2020.1749839.

Evropska komisija, Migracije in notranje zadeve (2020), https://ec.europa.eu/home-affairs/what-we-do/policies/irregular-migration-return-policy/facilitationirregular-migration_en (22. 1. 2020).

Grad Subotice (2015). Više od 200 taksija oduzeto zbog prevoza migranata, https:// gradsubotica.co.rs/vise-od-200-taksija-oduzeto-zbog-prevoza-migranata/ 10. 2020).

Hale, R. Charles (2001). What is Activist Research? ITEMS, Social Science Research Council, https://items.ssrc.org/from-our-archives/what-is-activist-research/ (16. 11. 2020).

Haraway, Donna (1988). Situated Knowledges: The Science Question in Feminism and the Privilege of Partial Perspective. Feminist Studies 14/3, 575-599, https:// philpapers.org/archive/harskt.pdf (18. 11. 2020).

Info Kolpa (2019). Poročilo o nezakonitih kolektivnih izgonih na slovensko-hrvaški meji. Časopis za kritiko znanosti 47/278, 81-113.

Jalušič, Vlasta (2019). Criminalizing "Pro-immigrant" Initiatives: Reducing the Space of Human Action. Dve domovini / Two Homelands 49, 105-123, https://doi. org/10.3986/dd.v0i49.7256.

Jones, Reece (2017). Nasilne meje. Ljubljana: Zložba *cf.

Kazenski zakonik Republike Slovenije (Uradni list RS, št. 50/12 - uradno prečiščeno besedilo $6 / 16$ - popr., 54/15, 38/16, 27/17, 23/20 in 91/20).

Khosravi, Shahram (2010). 'Illegal traveler.' An Auto-ethnography of Borders. Palgrave Macmillan, https://doi.org/10.1057/9780230281325.

Konvencija o statusu beguncev (1951). UNHCR, https://www.unhcr.org/si/wpcontent/uploads/sites/25/2017/06/1951_Convention_status_refugees-svn.pdf (21. 3. 2020). 
Klemp, Pia (2019). Why I Fight for Solidarity. TEDxBerin 2019, https://www.ted.com/ talks/pia_klemp_why_i_fight_for_solidarity (20.1. 2020).

Lilija, Ana (2020). Kriminalizacija migracij in solidarnosti. Diplomsko delo. Ljubljana: Fakulteta za socialno delo Univerze v Ljubljani, https://egradiva.fsd.uni-lj.si/search/ extshow/2417 (15. 11. 2020).

Lipovec Čebron, Uršula, Zorn, Jelka (2016). Avtonomija in nadzor migracij v evropskih stamponskih conah«. Dve domovini / Two Homelands 43, 61-75.

Lipovec Čebron, Uršula, Ivnik, Tina, Fekonja, Eva (2019). Migracije in gostoljubje: Kriminalizacija gostoljubja v Veliki Kladuši. Časopis za kritiko znanosti 47/278, 135-161.

Lunaček, Sarah (2019). Posledice eksternalizacije politike migracij Evropske unije v Agadezu (Niger). Časopis za kritiko znanosti 47/278, 56-80.

Majidi, Nassim (2018). Community Dimensions of Smuggling: The Case of Afganistan and Somalia. The ANNALS. American Academy of Political and Social Science 676/1, 97-113, https://doi.org/10.1177/0002716217751895.

Malek, Nastja (2020). Življenjski svet tihotapca migrantov. Magistrsko delo. Ljubljana: Fakulteta za socialno delo Univerze v Ljubljani.

Mardini, Sarah (2020). How I was Arrested for Handing out Blankets to Refugees. TEDxLondonWomen, https://www.youtube.com/watch?v=oNBQ-IYS5so (26. 6. 2020).

Ministrstvo za notranje zadeve RS (2018). Ministrica: V Sloveniji ne odrekamo pravice do mednarodne zaščite, 7. 9. 2018, http://mnz.arhiv-spletisc.gov.si/si/novinarsko_sredisce/novica/10383/index.html (11. 9. 2020).

Močnik, Borja, Mrevlje, Neža, Pistotnik, Sara (2002). Sodobni tihotapci: Raziskava nezakonitega prevozništva v Sloveniji. $V$ zoni prebežništva: Antropološke raziskave prebežnikov v Sloveniji (ur. Uršula Lipovec Čebron). Ljubljana: Oddelek za etnologijo in kulturno antropologijo Filozofske fakultete Univerze v Ljubljani, 183-224.

Mohammadi, Abdullah, Nikmar, Ruta, Savage, Emily (2019). "We are the ones they come to when nobody can help" Afghan Smugglers' Perceptions of themselves and their Communities. Geneva: IOM, https://publications.iom.int/books/mrs-no-56-we-are-ones-they-come-when-nobody-can-help-afghan-smugglersperceptions-themselves (15. 3. 2020).

Protokol ZN proti tihotapljenju migrantov po kopnem, morju in zraku (2000), zakon o ratifikaciji protokola, https://www.uradni-list.si/glasilo-uradni-list-rs/vsebina/ 2004-02-0050?sop=2004-02-0050 (27. 12. 2019).

Rackette, Carola (2019). Exclusive: Carola Rackete, the Sea-Watch Captain Taken to Court over Migrant Rescues. France 24, 20. 9. 2019, https://www.youtube.com/ watch?v=FYDTdxoNlso (27. 9. 2020).

Sanchez, Gabriella (2017). Critical Perspectives on Clandestine Migration Facilitation: An Overview of Migrant Smuggling Research. Journal on Migration and Human Security 5/1, 9-27, https://doi.org/10.1177/233150241700500102.

Sen, Somdeep (2018). Writing the "Refugee Crisis": Proposals for Activist Research. Syrian Refugee Children in the Middle East and Europe (ur. Michelle Pace, Somdeep Sen). London, New York: Routledge, 101-112, https://doi.org/10.4324/9781351169325-9. 
Stojić Mitrović, Marta, Meh, Ela (2015). The Reproduction of Borders and the Contagiousness of Illegalisation: A Case of a Belgrade Youth Hostel. Glasnik etnografskog instituta 63/3, 623-639, https://doi.org/10.2298/gei1503623s.

Šumi, Irena, Luthar, Oto (ur.) (2016). Slovenski pravični med narodi. Ljubljana: Založba ZRC, https://doi.org/10.3986/9789612548643.

Tazzioli, Martina (2018). Crimes of Solidarity. Migration and Containment through Rescue. Radical Philosophy 2.01, Creative Commons BY-NC-ND, https://www. radicalphilosophy.com/commentary/crimes-of-solidarity (3. 2. 2020).

Varuh človekovih pravic (2018). Vmesno (s)poročilo o aktivnostih in ugotovitvah Varuha o očitkih policistom, da zavračajo možnosti podajanja prošenj za mednarodno zaščito, http://www.varuh-rs.si/medijsko-sredisce/sporocila-za-javnosti/ novice/detajl/vmesno-sporocilo-o-aktivnostih-in-ugotovitvah-varuha-glede-ocitkov-zavracanja-moznosti-podajan/ (10. 12. 2018).

Veršić, Marin (2019). Bihać: 30.000 eura kazni zbog pružanja ilegalnog smještaja migrantima. Aljazeera Balkans 18. 6. 2019, http://balkans.aljazeera.net/video/ bihac-30000-eura-kazni-zbog-pruzanja-ilegalnog-smjestaja-migrantima?fbclid=IwAR3jH8-KLkOtyFIVvFIIAuwMtwGtQMcwBQKGKrRCEcIX8AF1-Dxc1wphvFc (4. 2. 2020).

Vosyliūtè, Lina, Conte, Carmine (2019). Crackdown on NGOs and Volunteers Helping Refugees and other Migrants. ReSoma, http://www.resoma.eu/sites/resoma/ resoma/files/policy_brief/pdf/Final\%20Synthetic\%20Report\%20\%20Crackdown $\% 20$ on $\% 20$ NGOs\%20and\%20volunteers $\% 20$ helping $\% 20$ refugees $\% 20$ and\%20other\%20migrants_1.pdf (17. 3. 2020).

Watson, Scott (2015). The Criminalization of Human and Humanitarian Smuggling. Migration, Mobility and Displacement 1/1, 39-53, https://doi.org/10.18357/ mmd11201513273.

Witkin, Stanley L. (2014). Narrating Social Work through Autoethnography. Columbia University Press, https://doi.org/10.7312/witk15880.

Zaviršek, Darja (2017). The Humanitarian Crisis of Migration Versus the Crisis of Humanitarianism: Current Dimensions and Challenges for Social Work Practice, Social Work Education, https://doi.org/10.1080/02615479.2017.1303043.

Zhang X, Sheldon, Sanchez, Gabriella E., Achilli, Luigi (2018). Crimes of Solidarity in Mobility: Alternative Views on Migrant Smuggling. The ANNALS. American Academy of Political and Social Science 676/1, 6-15, https://doi. org/10.1177/0002716217746908. 


\section{SUMMARY}

\section{THE EUROPEAN BORDER REGIME: PEOPLE SMUGGLING AND THE PARADOX OF THE CRIMINALIZATION OF SOLIDARITY Jelka ZORN}

The article discusses people smuggling in the context of violent borders (Jones 2017). It addresses the right to asylum, deconstructs the demonization of smugglers, and sheds light on the paradox of the criminalization of solidarity. The key research perspective is auto-ethnographic, contextualizing the author's own experience of helping people on the move and also being criminalized for this aid. Other research methods are interviews and the use of secondary sources. The author's experience urged her to address not only the criminalization of solidarity but also the mainstream image of human smugglers. EU anti-smuggling legislation flattens the differences between smuggling and solidarity practices since the material benefit of helping people on the move is not a necessary element to qualify as criminal activity. The author presents the embeddedness of the smuggling-solidarity antagonism along the same continuum in the context of violent borders and state persecution.

Differently from the state accounts, ethnographic studies present the perspective of migrants and smugglers themselves, which disputes the binary "victimpredator" and "humanitarian-for-profit" positioning (Mohamamadi, Nikmar, Savage 2019; Majidi 2018; Zhang, Shanchez, Achilli 2018). In reality, refugee-smuggler roles may intertwine in the same person. Ethnographers emphasize that collective migration-specific knowledge is needed: smugglers and migrants alike are part of the communities-of-knowledge-in-mobility (Ayalew Mengiste 2018). The states' combat against criminal networks results in criminalizing the normal commercial activities of taxi drivers and accommodation services in the externalized European border in Africa as well as on the Balkan route. The author further deconstructs the demonization of smugglers by presenting a case of smuggling as political activism. Solidarity practices surpass both capitalist free market relations and states' monopoly to control borders. The article concludes that solidarity work not only helps people on the move but also protests against police violence and the current system of border control. 